Louisiana State University

LSU Digital Commons

$7-1-2014$

\title{
Chronic stress alters concentrations of corticosterone receptors in a tissue-specific manner in wild house sparrows (Passer domesticus)
}

Christine R. Lattin

Tufts University

L. Michael Romero

Tufts University

Follow this and additional works at: https://digitalcommons.Isu.edu/biosci_pubs

\section{Recommended Citation}

Lattin, C., \& Romero, L. (2014). Chronic stress alters concentrations of corticosterone receptors in a tissue-specific manner in wild house sparrows (Passer domesticus). Journal of Experimental Biology, 217 (14), 2601-2608. https://doi.org/10.1242/jeb.103788

This Article is brought to you for free and open access by the Department of Biological Sciences at LSU Digital Commons. It has been accepted for inclusion in Faculty Publications by an authorized administrator of LSU Digital Commons. For more information, please contact ir@lsu.edu. 


\title{
Chronic stress alters concentrations of corticosterone receptors in a tissue-specific manner in wild house sparrows (Passer domesticus)
}

\author{
Christine R. Lattin* and L. Michael Romero
}

\begin{abstract}
The physiological stress response results in release of glucocorticoid hormones such as corticosterone (CORT). Whereas short-term activation of this response helps animals cope with environmental stressors, chronic activation can result in negative effects including metabolic dysregulation and reproductive failure. However, there is no consensus hormonal profile of a chronically stressed animal, suggesting that researchers may need to look beyond hormone titers to interpret the impacts of chronic stress. In this study, we brought wild house sparrows (Passer domesticus) into captivity. We then compared glucocorticoid and mineralocorticoid receptor concentrations in sparrows exposed either to a standardized chronic stress protocol $(n=26)$ or to standard husbandry conditions (controls; $n=20$ ). We used radioligand binding assays to quantify receptors in whole brain, liver, kidneys, spleen, gonads, gastrocnemius and pectoralis muscle, omental and subcutaneous fat, and bib and back skin. In most tissues, CORT receptors did not differ between controls and stressed animals, although we found marginal increases in receptor density in kidney and testes in stressed birds at some time points. Only in pectoralis muscle was there a robust effect of chronic stress, with both receptor types higher in stressed animals. Increased pectoralis sensitivity to CORT with chronic stress may be part of the underlying mechanism for muscle wasting in animals administered exogenous CORT. Furthermore, the change in pectoralis was not paralleled by gastrocnemius receptors. This difference may help explain previous reports of a greater effect of CORT on pectoralis than on other muscle types, and indicate that birds use this muscle as a protein reserve.
\end{abstract}

KEY WORDS: Hypothalamic-pituitary-adrenal axis, Glucocorticoids, Peripheral receptors, Bird

\section{INTRODUCTION}

Activation of the hypothalamus-pituitary-adrenal (HPA) axis results in the release of glucocorticoid hormones (cortisol and/or corticosterone depending on the species, hereafter CORT). At baseline concentrations, CORT helps regulate metabolism, activity levels and feeding behavior; at the higher concentrations caused by a stressor, CORT is an essential component of the vertebrate stress response (Landys et al., 2006; Sapolsky et al., 2000). During the stress response, CORT helps animals mobilize energy stores, enhances certain immune components and promotes escape and selfmaintenance behaviors (Spencer et al., 2001; Wingfield and Kitaysky, 2002).

Department of Biology, Tufts University, Medford, MA 02155, USA.

*Author for correspondence (christine.lattin@tufts.edu)

Received 7 February 2014; Accepted 26 April 2014
However, sustained high levels of CORT due to frequent or prolonged stressors can result in a number of stress-related pathologies, including suppression of reproduction and the immune system, metabolic dysregulation and cognitive impairment (Dallman et al., 2003; de Kloet et al., 2005; Martin, 2009; Sapolsky et al., 2000). Chronic stress is thought to result once CORT and other physiological mediators of the stress response become harmful, rather than helpful in re-establishing homeostasis and the normal activities of an animal's life history stage (McEwen and Wingfield, 2003; Romero et al., 2009). However, diagnosing chronic stress is not simple - the effects of presumed cases of chronic stress vary by species, stress paradigm, life history stage and other factors (Dickens and Romero, 2013; Lattin et al., 2012a). A recent review found no consensus profile in baseline, stress-induced or integrated CORT, negative feedback or HPA axis sensitivity associated with chronic stress (Dickens and Romero, 2013): different studies report an increase, a decrease or no change in each of these parameters. This diversity of results means it is not possible to simply examine CORT titers to distinguish between healthy and compromised animals. However, knowing whether animals are successfully coping with stressors or suffering deleterious effects from an overactive HPA axis can be crucial for diagnosing the health of an individual animal. An approach that goes beyond quantification of plasma CORT concentrations may therefore be necessary.

Most of CORT's effects occur via intracellular receptors that, when activated, bind to DNA and alter gene transcription (Rousseau and Baxter, 1979). There are over 4000 glucocorticoid-specific response elements in DNA, which can lead to enhanced or suppressed transcription of more than 200 different genes (Reddy et al., 2009). For a given exposure to the same amount of circulating hormone, higher receptor density in a target tissue would enhance that tissue's response to the hormone signal. CORT receptors are thus as important a component of the HPA axis as CORT itself, making them a good potential candidate for identifying effects of chronic stress. CORT receptors are ubiquitous throughout the body in both mammals (Ballard et al., 1974) and birds (Lattin et al., 2012b), and although CORT receptor dysregulation during chronic stress has only been examined in a few tissues, those studies suggest that receptors may provide insight into the transition from helpful to harmful CORT-mediated effects that occurs with chronic stress. For example, CORT receptor changes in brain areas such as the hippocampus may contribute to the attenuation of the negative feedback response in chronically stressed rats (Mizoguchi et al., 2003), and increased access of CORT to receptors in rat spleen may be part of the mechanism for chronic-stress-induced immunosuppression (Spencer et al., 1996).

Two intracellular receptors for CORT have been characterized in both mammals and birds - the high-affinity, low-capacity mineralocorticoid receptor (MR), found in relatively high 
concentrations in brain, kidney, liver and testes and in lower concentrations in other tissues (Breuner et al., 2003; Funder, 2005; Lattin et al., 2012b), and the low-affinity, high-capacity glucocorticoid receptor (GR), which appears practically ubiquitous, occurring in metabolic and immune tissues and throughout the brain (Ballard et al., 1974; Lattin et al., 2012b; Schmidt et al., 2010; Wada and Breuner, 2010). In mammals, MR seems primarily responsible for mediating baseline effects of CORT, whereas GR and MR work together to mediate the response to acute stress (De Kloet et al., 1998). Although several studies have examined chronic-stress induced changes in GR and MR in the brain (e.g. Dickens et al., 2009; Mizoguchi et al., 2003; Sapolsky et al., 1984), the effects of chronic stress on peripheral GR and MR are much less well understood.

This study aimed to elucidate the effects of chronic stress by comparing whole-tissue concentrations of intracellular CORT receptors in wild house sparrows [Passer domesticus (Linnaeus 1758)] brought into captivity and subjected to either a standardized stress protocol (Awerman and Romero, 2010; Cyr et al., 2007; Rich and Romero, 2005) or standard husbandry conditions. We quantified receptors in brain, liver, spleen, subcutaneous and omental fat, pectoralis and gastrocnemius muscle, gonads, kidney, and back and bib skin. House sparrow GR and MR have been characterized in these tissues (Breuner and Orchinik, 2009; Lattin et al., 2012b), and because these tissues are involved in immune function, metabolism, reproduction and negative feedback regulation, four processes known to be adversely affected by chronic stress (Table 1), they are good candidates for identifying potential effects of chronic stress on receptor density. We hypothesized that increased tissue sensitivity to CORT may be part of what causes pathology during chronic stress. Based on this hypothesis, we predicted that we would see increased receptor concentrations in most tissues of chronically stressed animals relative to controls (Table 1). However, based on several studies showing decreased CORT negative feedback and receptor expression in related brain areas with chronic stress (Dickens et al., 2009; Mizoguchi et al., 2003; Sapolsky et al., 1984), we predicted decreased receptor concentrations in the brains of chronically stressed animals relative to controls.

\section{RESULTS}

\section{Body mass and plasma CORT}

Although body mass varied significantly by sex (data not shown; $\left.F_{1,54.2}=5.2, P=0.026\right)$, there was no significant effect of treatment on body mass $\left(F_{1,54.2}=0.00, P=0.98\right)$ nor was there an interaction between sex and treatment $\left(F_{1,54.2}=0.2, P=0.66\right)$. There were no differences in baseline CORT between control animals and any of the stressed
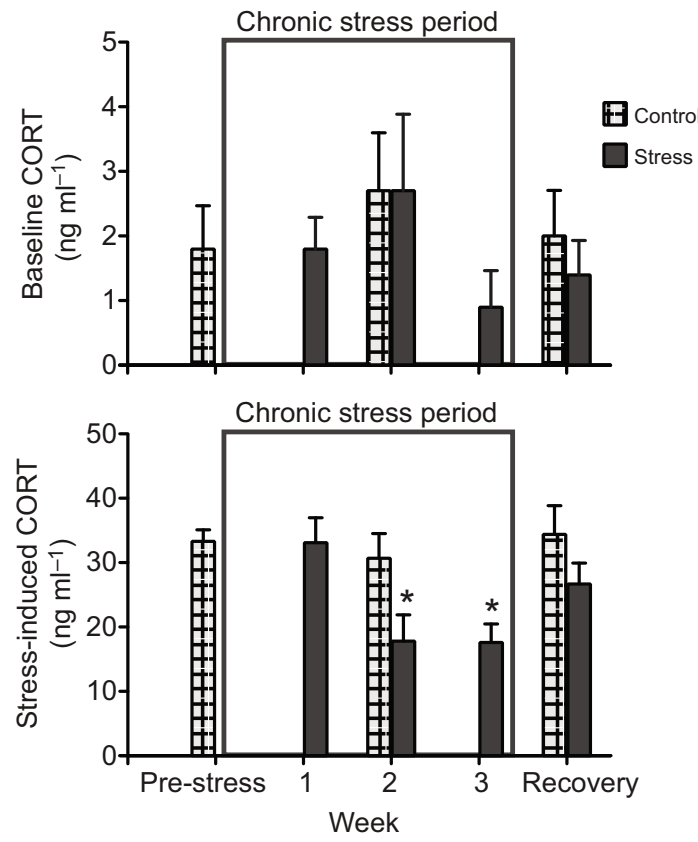

Fig. 1. Animals subjected to a standardized chronic stress protocol had lower stress-induced corticosterone, but not baseline corticosterone, than control animals. Plasma corticosterone concentrations at baseline (top) or in response to $30 \mathrm{~min}$ of restraint (bottom) in house sparrows exposed to a standardized chronic stress protocol for 1 week $(n=6), 2$ weeks $(n=6)$ or 3 weeks $(n=8)$, or after 3 weeks of stress and a 1-week recovery period $(n=5)$, and unstressed controls $(n=20)$. Half the birds were male and half female in each group, and each bird was only sampled once. Asterisks represent stressed groups that were significantly different from pooled controls. Data are means \pm s.e.m.

groups $\left(F_{4,15}=0.95, P=0.46\right.$; Fig. 1$)$. Stress-induced CORT, however, varied by treatment $\left(F_{4,41}=6.37, P=0.0004\right)$; compared with controls, stress-induced CORT was reduced in birds in weeks 2 and 3 of the chronic stress period ( $P=0.0038$ and $P=0.0010$, respectively).

\section{Receptors}

There were no differences in receptor concentration between controls and any of the stress groups for GR or MR in most tissues (Fig. 2): back skin (GR: $F_{4,39}=0.30, P=0.88$; MR: $F_{4,11.3}=0.20$, $P=0.93$ ); bib skin (GR: $F_{4,40}=0.57, P=0.68 ; \mathrm{MR}: F_{4,15}=1.20$, $P=0.35$ ); brain (GR: $F_{4,40}=0.99, P=0.42$; MR: $F_{4,40}=1.69, P=0.17$ ); gastrocnemius muscle (GR: $F_{4,40}=0.83, P=0.51$; MR: $F_{4,40}=1.36$,

Table 1. Summary of the effects of chronic stress on different physiological systems, and subsequent predictions about the effects of chronic stress on receptor density in associated tissues

\begin{tabular}{|c|c|c|c|}
\hline Physiological system & Associated tissues & Effects of chronic stress on this system & Predictions for this study \\
\hline Immune & Spleen, skin & $\begin{array}{l}\text { Immuno-suppression (Dhabhar and McEwen, 1997; } \\
\text { Martin, 2009) }\end{array}$ & Increased receptor density in spleen and skin \\
\hline Metabolic & Fat, muscle, liver, kidney & $\begin{array}{l}\text { Hyperglycemia } \\
\text { Muscle wasting } \\
\text { Obesity, especially abdominal fat hypertrophy } \\
\text { (Awerman and Romero, 2010; Bartolomucci et al., } \\
\text { 2009; Dallman et al., 2003; Lankford et al., 2005; } \\
\text { McCowen et al., 2001) }\end{array}$ & $\begin{array}{l}\text { Increased receptor density in muscle, fat } \\
\text { (especially omental), liver and kidney }\end{array}$ \\
\hline Reproductive & Ovary, testes & $\begin{array}{l}\text { Reproductive suppression (Sapolsky, 1985; Tilbrook } \\
\text { et al., 2000; Wingfield and Sapolsky, 2003) }\end{array}$ & Increased receptor density in gonads \\
\hline Regulatory & Brain & $\begin{array}{l}\text { Downregulation of negative feedback, and receptor } \\
\text { expression in related brain areas (Dickens et al., } \\
\text { 2009; Mizoguchi et al., 2003; Sapolsky et al., 1984) }\end{array}$ & Decreased receptor density in brain \\
\hline
\end{tabular}



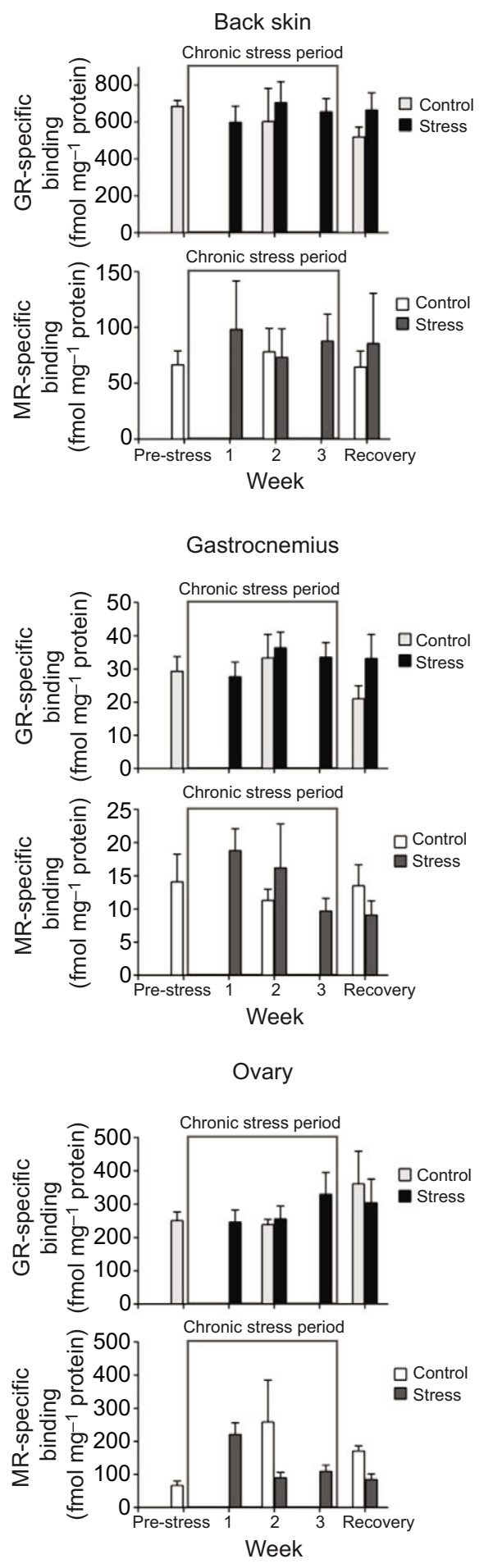

Bib skin
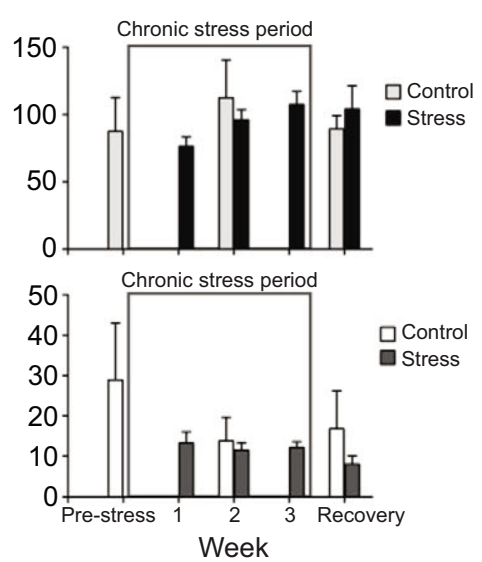

Liver
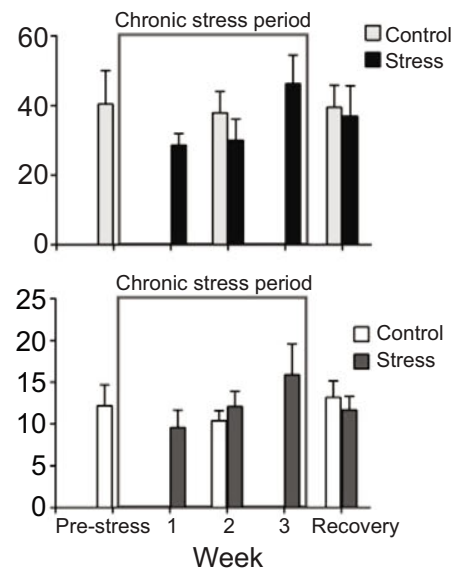

Spleen
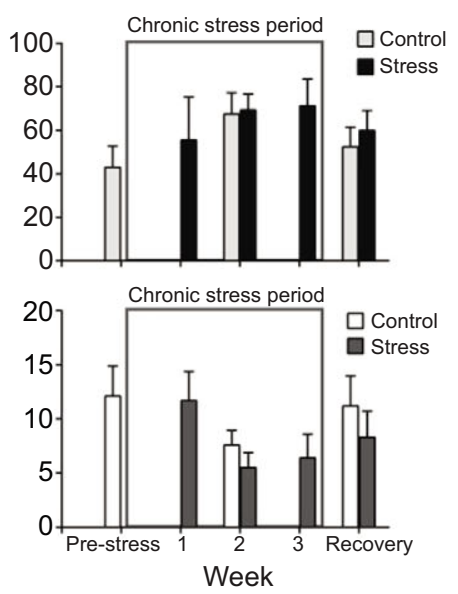

Brain

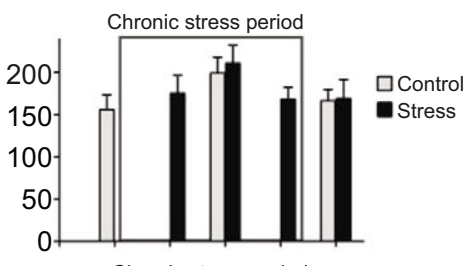

Chronic stress period

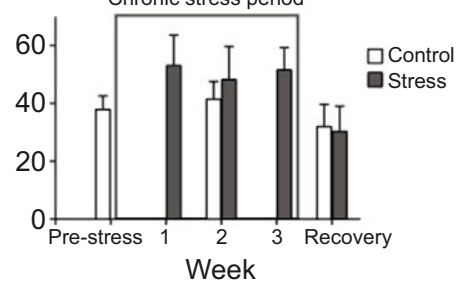

Omental fat
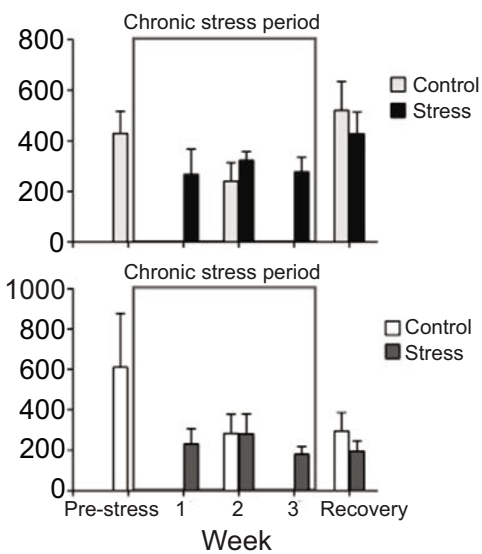

Subcutaneous fat
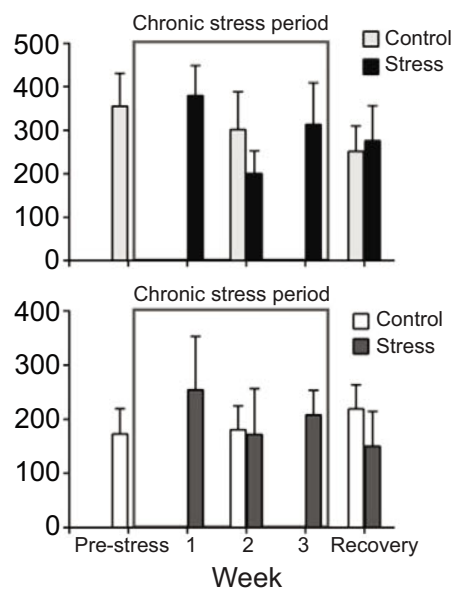

Fig. 2. In most tissues, glucocorticoid and mineralocorticoid receptor concentrations did not differ between animals exposed to a standardized chronic stress protocol and control animals. Intracellular concentrations of glucocorticoid receptors (GR, top graphs) or mineralocorticoid receptors (MR, bottom graphs) in nine tissues of house sparrows exposed to a standardized chronic stress protocol for 1 week $(n=6), 2$ weeks ( $n=6)$ or 3 weeks ( $n=8)$, or after 3 weeks of stress and a 1-week recovery period $(n=5)$, and unstressed controls $(n=20)$. Half the birds were male and half female in each group (except for ovary, where sample sizes were 3, 3, 4 and 3 for stress groups, and 10 for controls), and each bird was only sampled once. In these tissues, none of the stressed groups were significantly different from pooled controls. Data are means \pm s.e.m.

$P=0.27$ ); liver (GR: $F_{4,40}=1.15, P=0.35$; MR: $F_{4,40}=1.00, P=0.42$ ); omental fat (GR: $F_{4,37}=0.96, P=0.44$; MR: $F_{4,37}=0.90, P=0.47$ ); ovary (GR: $F_{4,18}=0.30, P=0.88$; MR: $F_{4,18}=1.22, P=0.34$ ); spleen (GR: $F_{4,39}=0.71, P=0.59$; MR: $F_{4,39}=1.46, P=0.23$ ); or subcutaneous fat (GR: $F_{4,40}=0.69, P=0.61$; MR: $F_{4,40}=0.38, P=0.82$ ).
There were significant differences in receptor concentrations between controls and one or more of the stress groups for three tissues: pectoralis muscle, testes and kidney (Fig. 3). Pectoralis GR concentrations in birds from stress weeks 2 and 3 and recovery were all higher than controls (GR full model: $F_{4,40}=3.18, P=0.023$; 

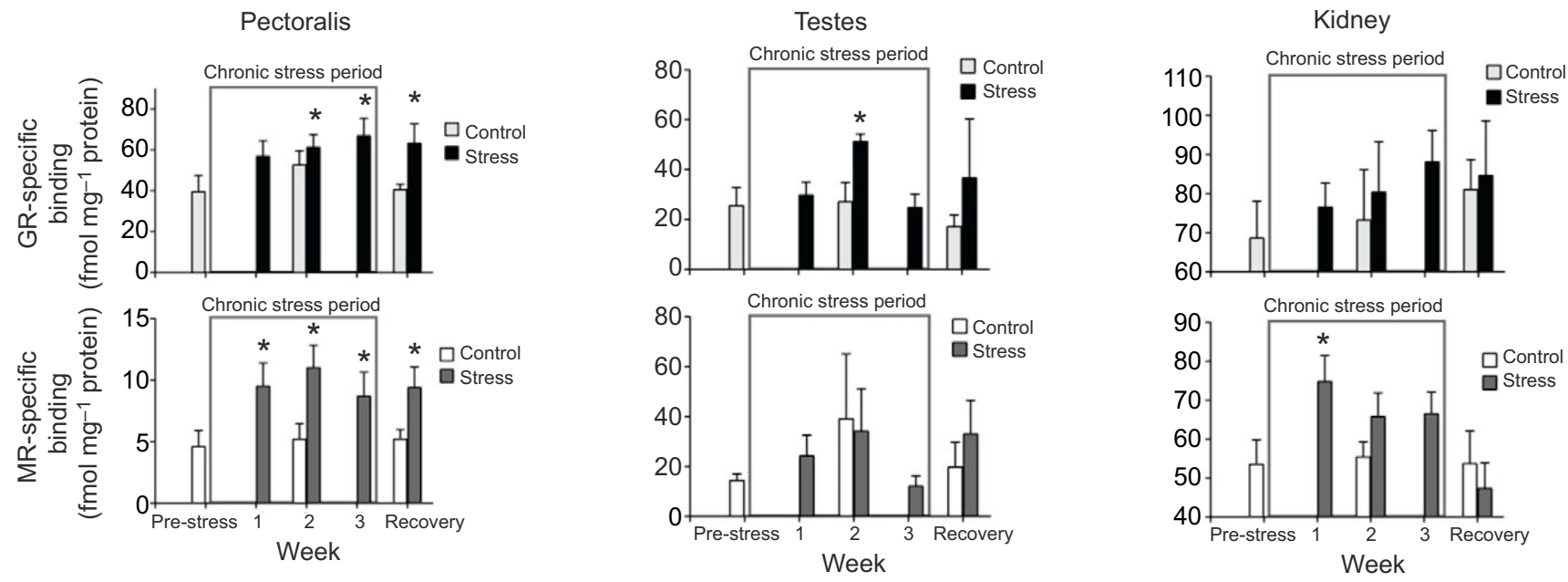

Fig. 3. In three tissues, glucocorticoid and mineralocorticoid receptor concentrations were higher in animals exposed to a standardized chronic stress protocol compared to control animals. Intracellular concentrations of glucocorticoid receptors (GR, top graphs) or mineralocorticoid receptors (MR,

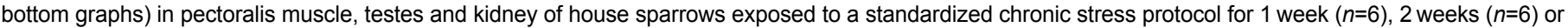

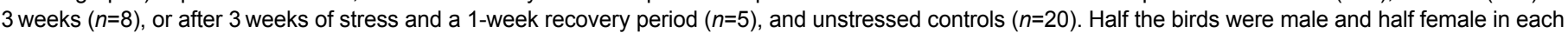
group (except for the testes, where sample sizes were 3, 3, 4 and 2 for stress groups, and 10 for controls), and each bird was only sampled once. Asterisks represent stress groups that were significantly different from pooled controls, although results for kidney and testes were not significant following sequential Bonferonni correction. Data are means \pm s.e.m.

controls compared with stress week 1: $P=0.13$; controls compared with stress week 2: $P=0.045$; controls compared with stress week 3: $P=0.0043$; controls compared with recovery: $P=0.038$ ). Pectoralis MR concentrations in birds from stress weeks 1, 2 and 3 and recovery were all higher than controls (MR full model: $F_{4,40}=4.13$, $P=0.0068$; controls compared with stress week $1: P=0.017$; controls compared with stress week 2: $P=0.0020$; controls compared with stress week 3: $P=0.030$; controls compared with recovery: $P=0.031$ ). Pectoralis mass did not differ between the controls and any of the stress groups $\left(F_{4,40}=0.63, P=0.65\right)$.

Although MR in kidney and GR in testes also changed during one treatment period during chronic stress (Fig. 3), after $P$-value correction using a sequential Bonferroni, only pectoralis MR and GR results remained significant. Kidney MR concentrations were higher in birds from stress week 1 compared with controls (GR: $F_{4,40}=0.48, P=0.75$; MR full model: $F_{4,40}=3.15, P=0.024$; controls compared with stress week 1: $P=0.0094$; controls compared with stress week 2: $P=0.13$; controls compared with stress week 3 : $P=0.078$; controls compared with recovery: $P=0.41$ ). Testes GR concentrations were higher in birds from stress week 2 compared with controls (GR full model: $F_{4,7.8}=7.75, P=0.030$; controls compared with stress week 1: $P=0.41$; controls compared with stress week 2: $P=0.0036$; controls compared with stress week 3: $P=0.78$; controls compared with recovery: $P=0.18$; MR: $F_{4,17}=0.48, P=0.75$ ). Testes mass did not differ between controls and any of the stress groups $\left(F_{4,17}=1.22, P=0.34\right)$.

\section{DISCUSSION}

Unlike an earlier study that examined HPA changes in house sparrows exposed to capture and 5 days of captivity (Lattin et al., 2012a), and studies in European starlings (Sturnus vulgaris) using the same chronic stress protocol (Cyr et al., 2007; Rich and Romero, 2005), we saw no decrease in body mass or baseline CORT in house sparrows exposed to 3 weeks of random, rotating stressors. However, similar to previous studies conducted using this protocol (Cyr et al., 2007; Rich and Romero, 2005), stressed birds did have a dampened response to acute stressors - animals euthanized during weeks 2 and 3 of the chronic stress period had significantly lower stress-induced CORT than controls. Several groups have proposed that this dampening of the HPA response during chronic stress is an attempt to avoid stress-related pathologies associated with chronically high CORT concentrations (Dallman et al., 2003; de Kloet et al., 2005; Martin, 2009). The differences between this and past studies also highlight the extent to which different types of chronic stressors (e.g. captivity versus random, rotating psychological stressors) may be perceived differently and therefore elicit different physiological responses, as well as the sometimesfrustrating role of species-specific effects. Given that house sparrows are a particularly successful human commensal and invasive species (Anderson, 2006), they may be more resilient to chronic stress than most species.

Based on the hypothesis that increased tissue sensitivity to CORT could contribute to adverse effects caused by chronic stress, we predicted that we would see increased GR and/or MR concentrations in all tissues except brain in wild-caught house sparrows exposed to a 3 week chronic stress protocol. Overall, there were relatively few changes in CORT receptors in house sparrows exposed to 3 weeks of random, unpredictable stressors, and small sample sizes prevented us from performing a more detailed analysis of receptor changes for each tissue by sex. We did, however, see increased CORT receptors in stressed birds relative to controls in three tissues: kidney, testes and pectoralis.

Kidney MR was higher in stressed birds euthanized during week 1 of the chronic stress period compared with controls. Kidney MR is typically thought to be a target of the mineralocorticoid hormone aldosterone rather than CORT: in mammals, the enzyme 11 $\beta$ hydroxysteroid dehydrogenase type 2 (11ßHSD2) converts CORT to an inactive metabolite in kidney, leaving MR free to bind aldosterone to regulate sodium balance (Edwards et al., 1988). Avian kidney also shows high 11ßHSD2-like activity (Kučka et al., 2006), suggesting that avian kidney MR may also be more of a target for aldosterone. During the first week of chronic stress, when sparrows presumably experienced several acute increases in CORT concentrations over the course of each day due to stressor administration, it is possible that 
animals may have also experienced changes in sodium balance that could necessitate an increase in MR. It is also possible that MR in avian kidney may be a target for CORT as well as aldosterone, although little is known about CORT's specific actions on avian kidney, making these results difficult to interpret.

We also saw increased GR in testes of males euthanized during week 2 of the chronic stress period. During an acute stress response, CORT is thought to primarily suppress reproduction at the level of the brain and pituitary (Breen and Karsch, 2006; Rivier and Rivest, 1991). However, over longer time scales, CORT can suppress steroidogenesis and other reproductive processes by acting directly on the ovary and testes (Consten et al., 2002; Hsueh and Erickson, 1978; Sapolsky, 1985). Increased receptor density in gonadal tissue, such as seen in the present study, could augment this effect and contribute to chronic stress-induced reproductive suppression. While exogenous CORT administration clearly causes gonadal regression in birds (Hull et al., 2007; Pilo et al., 1985), we saw no difference in the testes mass of stressed males compared with controls. Therefore, both chronic stress and increased testes GR were not enough to cause regression of the testes, which may be in part because sparrows also downregulated their acute stress response (Fig. 1).

The strongest effect of the chronic stress protocol on receptor concentrations was seen in pectoralis muscle, where both GR and MR were higher in most of the stressed groups of animals than in controls. These receptor differences even persisted in birds euthanized 1 week after the cessation of the chronic stress protocol. CORT both increases proteolysis and inhibits protein synthesis, freeing up amino acids to be used as substrates for gluconeogenesis (Hasselgren, 1999; Sapolsky et al., 2000). Because of this catabolic role, exogenous CORT administered through diet, implants or injections typically causes muscle wasting (Busch et al., 2008; Gray et al., 1990; Hull et al., 2007; Tomas et al., 1979); in mammals, this muscle-wasting effect is mediated by GR (Watson et al., 2012). Increased muscle receptor density in response to chronic stress, perhaps as part of a shift towards protein as an energy source, could help explain why muscle wasting occurs in these studies.

The difference between the pectoralis and the gastrocnemius was striking. We did not see an increase in GR or MR in gastrocnemius muscle, which is consistent with previous studies showing that the pectoralis may be particularly affected by CORT compared with other muscle types, especially in birds (Honey, 1990; Lin et al., 2006; Yuan et al., 2008). Because the pectoralis can account for $\sim 10-25 \%$ of a bird's total body mass (Lundgren and Kiessling, 1988), some have suggested it could be mobilized selectively as a kind of 'labile protein reserve' (Kendall et al., 1973; Ward, 1969). Because of the important role of the pectoralis in avian flight, this increased sensitivity to CORT could cause problems if stressors were to persist - if a sparrow mobilizes too much muscle for energy, it reduces its ability to flee stressors. However, as with the testes, we saw no differences in pectoralis mass between stressed birds and controls in this study, possibly because of downregulation of the acute stress response.

In summary, although CORT receptors in most tissues did not differ between control animals and birds exposed to a standardized protocol of random, rotating stressors, we did see receptor differences in some tissues that could potentially be used as indicators of chronic stress, and may help us understand some of the pathologies that can result from prolonged CORT exposure.

\section{MATERIALS AND METHODS}

\section{Study subjects}

House sparrows ( $n=46$, half males and half females) were caught at bird feeders in Arlington, Medford and Somerville, MA, USA using mist nets and Potter traps between 6 April and 22 May 2011. All birds used in this study were adults. Captured birds were housed together in an outdoor aviary with ad libitum water, grit and mixed seed. On 23 May 2011, birds were brought into the laboratory and housed doubly in cages (1 male, 1 female) under natural day length conditions ( $16 \mathrm{~h}: 8 \mathrm{~h}$ light:dark). Birds spent 2 weeks in the laboratory to adjust to laboratory conditions before the start of the experiment.

\section{Chronic stress protocol}

Control $(n=20)$ and stress birds ( $n=26)$ were housed in two different rooms in the laboratory, but exposed to identical husbandry conditions. We subjected stress birds to a 3-week standardized chronic stress protocol (Fig. 1) using 30 min stressors four times a day (Awerman and Romero, 2010; Cyr et al., 2007; Rich and Romero, 2005). The stressor type and time of administration were randomly determined, with at least $2 \mathrm{~h}$ between each stressor. The stressors used (being rolled on a cart, radio, restraint, human voice/presence and cage disturbance) have all been shown individually to significantly increase CORT titers (Nephew et al., 2003; Rich and Romero, 2005), and the chronic stress protocol has been found to cause changes in body mass, blood chemistry parameters, CORT titers, adrenal sensitivity, MR and GR expression in some brain areas, and offspring survival in wildcaught birds (Awerman and Romero, 2010; Cyr et al., 2007; Cyr and Romero, 2007; Dickens et al., 2009; Rich and Romero, 2005). Control birds were not subjected to the stressors (Fig. 4). After the 3-week chronic stress period, birds in the stress group were given 1 week to recover. Animals were euthanized every week in the stress group, and every other week in the control group, to determine the effects of chronic stress as the duration of stressors persisted, and to see whether these effects disappeared after a week of recovery (Fig. 4). All procedures involving birds were performed according to Association for Assessment and Accreditation of Laboratory Animal Care guidelines and were approved by the Tufts University Institutional Animal Care and Use Committee.

\section{Blood sampling, chemical adrenalectomy and CORT radioimmunoassay}

To compare our study with previous chronic stress studies that primarily measured CORT titers, we took blood samples from each bird to measure baseline and plasma CORT. All birds were sampled only once, $\sim 36 \mathrm{~h}$ before euthanization. Baseline blood samples were taken within 3 min of entering bird rooms (Romero and Reed, 2005). After $30 \mathrm{~min}$ of restraint in a cloth bag, a stress-induced blood sample was also taken.

To reduce endogenous CORT that would otherwise interfere with receptor binding assays (Breuner et al., 2000; McEwen et al., 1974), all house sparrows in both control and stressed groups received intramuscular injections of mitotane (ortho, para-DDD; $180 \mathrm{mg} \mathrm{kg}^{-1}$ body mass; SigmaAldrich, St Louis, MO, USA) $\sim 36$ and $\sim 24 \mathrm{~h}$ prior to euthanization (Breuner and Orchinik, 2001). The first mitotane injection was given immediately after sampling blood for baseline and stress-induced CORT.

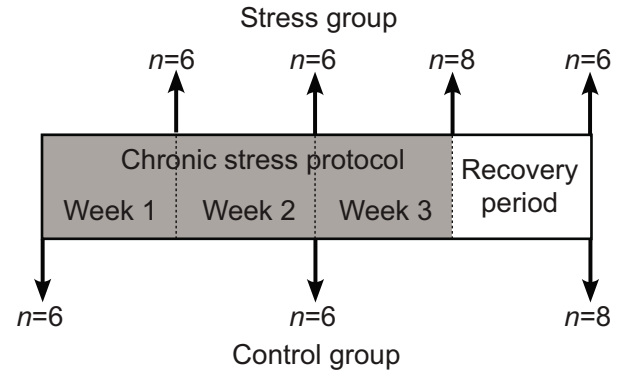

Fig. 4. Study design showing the 3-week chronic stress period and 1week recovery period (top) for the stressed group $(n=26)$ and 4 weeks of captivity (bottom) for the control group $(n=20)$ of wild-caught house sparrows sampled for blood and tissues at different time points. The two groups were housed separately to minimize disturbances on controls. One male from the stress recovery group died under anesthesia before perfusion; data from this bird were only used for body mass and hormone analyses, not tissue analyses. 
Mitotane appears to be quite specific in reducing circulating CORT and not affecting other steroid hormones (Sanderson, 2006); for example, 3 days of mitotane treatment did not affect circulating testosterone or testes mass in house sparrows (Breuner et al., 2000). Approximately $36 \mathrm{~h}$ after the first mitotane injection, birds were placed into cloth bags for $30 \mathrm{~min}$ and a blood sample was taken to determine the effectiveness of chemical adrenalectomy.

All blood samples were taken from the brachial vein using heparinized capillary tubes, and total blood volume taken did not exceed $1 \%$ of the bird's body mass (Fair et al., 2010). Blood samples were stored on ice for up to $6 \mathrm{~h}$, and then centrifuged. After centrifugation, plasma was removed and stored at $-20^{\circ} \mathrm{C}$.

We determined CORT concentrations in each sample using radioimmunoassay following the methods of Wingfield et al. (Wingfield et al., 1992). Briefly, samples were allowed to equilibrate overnight with a small amount of radiolabeled CORT to determine individual recoveries. CORT was extracted from each sample using freshly redistilled dichloromethane; the samples were then dried under nitrogen gas and resuspended in phosphate-buffered saline with $1 \%$ gelatin. Tritiated CORT and CORT antibody (B3-163, Esoterix, Calabasas Hills, CA, USA) were added to samples and standards and allowed to equilibrate. We added dextrancoated charcoal to adsorb unbound steroid, and separated bound from unbound fractions using centrifugation. The bound fraction was decanted, mixed with scintillation fluid and counted. Samples were assayed in duplicate, and assay values were corrected for individual recoveries following extraction. Mean recovery was $85 \%$. Inter- and intra-assay coefficients of variation were determined by running standards in each assay. Intra-assay variation was $3.5 \%$; inter-assay variation was $15.8 \%$.

\section{Tissue processing}

Birds were anesthetized with intramuscular injections of ketamine ( $\sim 80 \mathrm{mg} \mathrm{kg}^{-1}$ body mass; Fort Dodge Animal Health, Fort Dodge, IA, USA) and xylazine ( $\sim 20 \mathrm{mg} \mathrm{kg}^{-1}$ body mass; Akorn, Inc., Decatur, IL, USA), at doses appropriate for house sparrows (Muresan et al., 2008). Sparrows were transcardially perfused with ice-cold heparinized saline, and whole brain, liver, right pectoralis muscle, left and right gastrocnemius muscles, subcutaneous fat from the furcula, omental fat from the abdomen, spleen, gonads, bib skin (the ventral patch of skin beginning under the beak and ending halfway down the pectoralis muscle) and back skin (the dorsal patch of skin from the nape to the tail) were removed and flash-frozen on dry ice. Tissues were always taken in the same order, and the time to take all tissues was recorded for each bird (mean time $=13.5 \pm 1.3 \mathrm{~min}$ ). Tissues were stored at $-80^{\circ} \mathrm{C}$ until assay.

\section{Receptor binding assays}

Receptor binding assays were performed following Breuner and Orchinik (Breuner and Orchinik, 2001), and have been described in detail elsewhere (Lattin et al., 2012b). We used homogenization techniques, tissue to buffer ratios, incubation times and temperatures optimized for each tissue type in house sparrows to maximize specific binding and minimize non-specific binding (Lattin et al., 2012b). Binding in individual samples was standardized per mg protein using Bradford assays. Each sample was run in triplicate, and for each tissue, all individuals were run in the same assay to eliminate inter-assay variation.

Briefly, whole tissues were homogenized in ice-cold buffer and spun in an ultracentrifuge to separate soluble proteins (including MR and GR) from nuclear, mitochondrial and microsomal proteins. Cytosol was incubated with $10 \mathrm{nmol}^{-1}\left[{ }^{3} \mathrm{H}\right] \mathrm{CORT}$ (PerkinElmer, Waltham, MA, USA) and one of the following: (1) buffer, to measure total binding; (2) $1 \mu \mathrm{mol}^{-1}$ unlabeled CORT (Sigma-Aldrich), to measure non-specific binding; or (3) $1 \mu \mathrm{mol} 1^{-1}$ RU486 (mifepristone; Tocris Bioscience, Minneapolis, MN, USA), which only binds GR (Breuner and Orchinik, 2009; Lattin et al., 2012b). After subtracting out non-specific binding, MR binding can be calculated directly from test tubes containing RU486; GR binding can be calculated by subtracting MR binding from total binding. Affinity estimates derived from previous equilibrium saturation analyses (Breuner and Orchinik, 2001; Lattin et al., 2012b) predict that $10 \mathrm{nmol}^{-1}\left[{ }^{3} \mathrm{H}\right]$ CORT should occupy $>95 \%$ of MR and $\sim 63 \%$ of GR. Incubations were terminated by rapid filtration, and filter paper was mixed with Ultima Gold scintillation fluid (PerkinElmer) and run on a scintillation counter (TriCarb 1600, PerkinElmer).

\section{Statistical analyses}

One male from the chronic stress recovery group died prematurely under anesthesia during perfusions. We used data from this bird for plasma CORT and body mass analyses, but not receptor analyses. We euthanized birds from the control group at three different time points to control for the effects of ongoing captivity (Fig. 1). As there were no differences in hormone titers or receptor concentrations in any tissue among control birds measured at the three different time points, control birds were pooled to simplify analysis. Therefore, all tissue analyses compared five different groups: controls $(n=20)$, stress week $1(n=6)$, stress week $2(n=6)$, stress week $3(n=8)$ and recovery $(n=5)$. In each group, half of the individuals were male, and half female (except for the recovery group, which contained two males and three females, as stated above).

Because we had multiple body mass measures for each individual, we analyzed mass data in a linear mixed model that included sex, date and treatment as fixed effects and individual as a random effect using Proc Mixed in SAS (SAS Institute, Cary, NC, USA). All other statistical analyses were performed using ANOVA in JMP version 10.0 (SAS Institute). ANOVA is fairly robust to violations of normality assumptions, but not to violations of homogeneity of variances (Quinn and Keough, 2002). All tissues came from the same 45 birds, and we considered combining receptor analyses for all tissues in ANOVA models including individual as a random effect to account for this; however, different tissues had significantly different variances in their error terms, and this heteroscedasticity problem violates the assumptions of this type of model (Sokal and Rohlf, 1981; Zuur et al., 2009). Therefore, we ran each tissue in a separate analysis with receptor concentration (GR or MR) as the dependent variable and treatment group (control, stress week 1, 2, 3 or recovery) as the independent variable. We ensured that data met the homogeneity of variances assumption using Levene's test (Quinn and Keough, 2002), and in situations where variances among sample groups were not homogeneous, we used Welch's ANOVA (Day and Quinn, 1989).

When the overall ANOVA was significant, we only examined comparisons ( $t$-tests) between controls and the four stressed groups, rather than all pair-wise comparisons (Day and Quinn, 1989; Ruxton and Beauchamp, 2008). When running multiple analyses, the odds of committing a type I error increases; however, because correcting $P$-values for multiple comparisons is not universally recommended (Feise, 2002; Perneger, 1998; Rothman, 1990), we present both uncorrected significant $P$ values and significant $P$-values after correction using a sequential Bonferroni test (Rice, 1989). In two tissues where receptor density varied significantly among treatments (see results), we also ran ANOVAs comparing tissue mass. Although each group contained equal numbers of males and females, sample sizes did not permit inclusion of sex as a factor in our analyses. However, previous studies of receptor density in different house sparrow tissues have not shown large sex differences (Breuner and Orchinik, 2001; Lattin and Romero, 2013; Lattin et al., 2013).

Samples containing 1-10 mg protein $\mathrm{ml}^{-1}$ buffer have been shown to produce accurate results for intracellular glucocorticoid receptor binding assays (López Bernal et al., 1984). Five individuals were excluded from

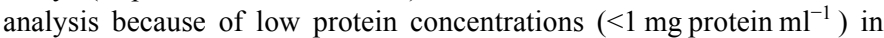
cytosol: back skin: one control female; omental fat: one control male, one stress male from week 1 and one stress female from week 2 ; and spleen: one stress female from week 1 .

\section{Acknowledgements}

The authors are grateful to M. McVey, K. McLaughlin and S. Lefebvre for providing field sites, and to R. de Bruijn, C. Bauer, K. Waldron-Francis, C. Medina, J. Cash, D. Merullo, L. Wang and C. Hui for assistance catching and sampling house sparrows and administering stressors. We also thank an anonymous reviewer for helpful feedback and suggestions on this manuscript.

\section{Competing interests}

The authors declare no competing financial interests. 
Author contributions

C.R.L. designed the study, executed the experiments, analyzed the data,

interpreted the findings, and wrote and revised the article. L.M.R. conceived of the study, designed the study, interpreted the findings and revised the article.

\section{Funding}

Funding was provided by an Environmental Protection Agency Science to Achieve Results Fellowship and a Tufts University Graduate Student Research Award to

C.R.L. and National Science Foundation IOS-1048529 to L.M.R.

\section{References}

Anderson, T. R. (2006). Biology of the Ubiquitous House Sparrow: From Genes to Populations. Oxford: Oxford University Press.

Awerman, J. L. and Romero, L. M. (2010). Chronic psychological stress alters body weight and blood chemistry in European starlings (Sturnus vulgaris). Comp. Biochem. Physiol. 156A, 136-142.

Ballard, P. L., Baxter, J. D., Higgins, S. J., Rousseau, G. G. and Tomkins, G. M. (1974). General presence of glucocorticoid receptors in mammalian tissues. Endocrinology 94, 998-1002.

Bartolomucci, A., Cabassi, A., Govoni, P., Ceresini, G., Cero, C., Berra, D. Dadomo, H., Franceschini, P., Dell'Omo, G., Parmigiani, S. et al. (2009). Metabolic consequences and vulnerability to diet-induced obesity in male mice under chronic social stress. PLOS ONE 4, e4331.

Breen, K. M. and Karsch, F. J. (2006). New insights regarding glucocorticoids, stress and gonadotropin suppression. Front. Neuroendocrinol. 27, 233-245.

Breuner, C. W. and Orchinik, M. (2001). Seasonal regulation of membrane and intracellular corticosteroid receptors in the house sparrow brain. J. Neuroendocrinol. $13,412-420$

Breuner, C. W. and Orchinik, M. (2009). Pharmacological characterization of intracellular, membrane, and plasma binding sites for corticosterone in house sparrows. Gen. Comp. Endocrinol. 163, 214-224.

Breuner, C. W., Jennings, D. H., Moore, M. C. and Orchinik, M. (2000) Pharmacological adrenalectomy with mitotane. Gen. Comp. Endocrinol. 120, 27-34.

Breuner, C. W., Orchinik, M., Hahn, T. P., Meddle, S. L., Moore, I. T., Owen-Ashley, N. T., Sperry, T. S. and Wingfield, J. C. (2003). Differential mechanisms for regulation of the stress response across latitudinal gradients. Am. J. Physiol. 285, R594-R600.

Busch, D. S., Sperry, T. S., Peterson, E., Do, C.-T., Wingfield, J. C. and Boyd, E. H. (2008). Impacts of frequent, acute pulses of corticosterone on condition and behavior of Gambel's white-crowned sparrow (Zonotrichia leucophrys gambelii). Gen. Comp. Endocrinol. 158, 224-233.

Consten, D., Lambert, J. G. D., Komen, H. and Goos, H. J. T. (2002). Corticosteroids affect the testicular androgen production in male common carp (Cyprinus carpio L.). Biol. Reprod. 66, 106-111.

Cyr, N. E. and Romero, L. M. (2007). Chronic stress in free-living European starlings reduces corticosterone concentrations and reproductive success. Gen. Comp. Endocrinol. 151, 82-89.

Cyr, N. E., Earle, K., Tam, C. and Romero, L. M. (2007). The effect of chronic psychological stress on corticosterone, plasma metabolites, and immune responsiveness in European starlings. Gen. Comp. Endocrinol. 154, 59-66.

Dallman, M. F., Pecoraro, N., Akana, S. F., La Fleur, S. E., Gomez, F., Houshyar, H., Bell, M. E., Bhatnagar, S., Laugero, K. D. and Manalo, S. (2003). Chronic stress and obesity: a new view of 'comfort food'. Proc. Natl. Acad. Sci. USA 100, 1169611701

Day, R. W. and Quinn, G. P. (1989). Comparisons of treatments after an analysis of variance in ecology. Ecol. Monogr. 59, 433-463.

De Kloet, E. R., Vreugdenhil, E., Oitzl, M. S. and Joëls, M. (1998). Brain corticosteroid receptor balance in health and disease. Endocr. Rev. 19, 269-301.

de Kloet, E. R., Joëls, M. and Holsboer, F. (2005). Stress and the brain: from adaptation to disease. Nat. Rev. Neurosci. 6, 463-475.

Dhabhar, F. S. and McEwen, B. S. (1997). Acute stress enhances while chronic stress suppresses cell-mediated immunity in vivo: a potential role for leukocyte trafficking. Brain Behav. Immun. 11, 286-306.

Dickens, M. J. and Romero, L. M. (2013). A consensus endocrine profile for chronically stressed wild animals does not exist. Gen. Comp. Endocrinol. 191, 177189

Dickens, M., Romero, L. M., Cyr, N. E., Dunn, I. C. and Meddle, S. L. (2009) Chronic stress alters glucocorticoid receptor and mineralocorticoid receptor mRNA expression in the European starling (Sturnus vulgaris) brain. J. Neuroendocrinol. 21, 832-840.

Edwards, C. R. W., Stewart, P. M., Burt, D., Brett, L., McIntyre, M. A., Sutanto, W. S., de Kloet, E. R. and Monder, C. (1988). Localisation of 11 beta-hydroxysteroid dehydrogenase - tissue specific protector of the mineralocorticoid receptor. Lancet 332, 986-989.

Fair, J., Paul, E. and Jones, J. (eds) (2010). Guidelines to the Use of Wild Birds in Research. Washington, DC: The Ornithological Council.

Feise, $R$. J. (2002). Do multiple outcome measures require p-value adjustment? BMC Med. Res. Methodol. 2, 8 .

Funder, J. W. (2005). Mineralocorticoid receptors: distribution and activation. Heart Fail. Rev. 10, 15-22.

Gray, J. M., Yarian, D. and Ramenofsky, M. (1990). Corticosterone, foraging behavior, and metabolism in dark-eyed juncos, Junco hyemalis. Gen. Comp. Endocrinol. 79, 375-384.
Hasselgren, P. O. (1999). Glucocorticoids and muscle catabolism. Curr. Opin. Clin. Nutr. Metab. Care 2, 201-205.

Honey, P. K. (1990). Avian Flight Muscle Pectoralis Major as a Reserve of Proteins and Amino Acids. MSc thesis, University of Washington, Seattle, WA, USA

Hsueh, A. J. W. and Erickson, G. F. (1978). Glucocorticoid inhibition of FSH-induced estrogen production in cultured rat granulosa cells. Steroids 32, 639-648.

Hull, K. L., Cockrem, J. F., Bridges, J. P., Candy, E. J. and Davidson, C. M. (2007). Effects of corticosterone treatment on growth, development, and the corticosterone response to handling in young Japanese quail (Coturnix coturnix japonica). Comp. Biochem. Physiol. 148A, 531-543.

Kendall, M. D., Ward, P. and Bacchus, S. (1973). A protein reserve in the pectoralis major flight muscle of Quelea quelea. Ibis 115, 600-601.

Kučka, M., Vagnerová, K., Klusonová, P., Miksík, I. and Pácha, J. (2006). Corticosterone metabolism in chicken tissues: evidence for tissue-specific distribution of steroid dehydrogenases. Gen. Comp. Endocrinol. 147, 377-383.

Landys, M. M., Ramenofsky, M. and Wingfield, J. C. (2006). Actions of glucocorticoids at a seasonal baseline as compared to stress-related levels in the regulation of periodic life processes. Gen. Comp. Endocrinol. 148, 132-149.

Lankford, S. E., Adams, T. E., Miller, R. A. and Cech, J. J., Jr (2005). The cost of chronic stress: impacts of a nonhabituating stress response on metabolic variables and swimming performance in sturgeon. Physiol. Biochem. Zool. 78, 599-609.

Lattin, C. R. and Romero, L. M. (2013). Seasonal variation in corticosterone receptor binding in brain, hippocampus and gonads in house sparrows (Passer domesticus). Auk 130, 591-598.

Lattin, C. R., Bauer, C. M., de Bruijn, R. and Michael Romero, L. (2012a). Hypothalamus-pituitary-adrenal axis activity and the subsequent response to chronic stress differ depending upon life history stage. Gen. Comp. Endocrinol. 178, 494501.

Lattin, C. R., Waldron-Francis, K., Richardson, J. W., de Bruijn, R., Bauer, C. M., Breuner, C. W. and Michael Romero, L. (2012b). Pharmacological characterization of intracellular glucocorticoid receptors in nine tissues from house sparrow (Passer domesticus). Gen. Comp. Endocrinol. 179, 214-220.

Lattin, C. R., Waldron-Francis, K. and Romero, L. M. (2013). Intracellular glucocorticoid receptors in spleen, but not skin, vary seasonally in wild house sparrows (Passer domesticus). Proc. R. Soc. B 280, 20123033.

Lin, H., Sui, S. J., Jiao, H. C., Buyse, J. and Decuypere, E. (2006). Impaired development of broiler chickens by stress mimicked by corticosterone exposure. Comp. Biochem. Physiol. 143A, 400-405.

López Bernal, A., Anderson, A. B. M. and Turnbull, A. C. (1984). The measurement of glucocorticoid receptors in human placental cytosol. Placenta 5, 105-116.

Lundgren, B. O. and Kiessling, K.-H. (1988). Comparative aspects of fibre types, areas, and capillary supply in the pectoralis muscle of some passerine birds with differing migratory behaviour. J. Comp. Physiol. B 158, 165-173.

Martin, L. B. (2009). Stress and immunity in wild vertebrates: timing is everything. Gen. Comp. Endocrinol. 163, 70-76.

McCowen, K. C., Malhotra, A. and Bistrian, B. R. (2001). Stress-induced hyperglycemia. Crit. Care Clin. 17, 107-124.

McEwen, B. S. and Wingfield, J. C. (2003). The concept of allostasis in biology and biomedicine. Horm. Behav. 43, 2-15.

McEwen, B. S., Wallach, G. and Magnus, C. (1974). Corticosterone binding to hippocampus: immediate and delayed influences of the absence of adrenal secretion. Brain Res. 70, 321-334.

Mizoguchi, K., Ishige, A., Aburada, M. and Tabira, T. (2003). Chronic stress attenuates glucocorticoid negative feedback: involvement of the prefrontal cortex and hippocampus. Neuroscience 119, 887-897.

Muresan, C., Czirjak, G. A., Pap, P. L. and Köbölkuti, L. B. (2008). Ketamine and xylazine anaesthesia in the house sparrow. Vet. Med. 65, 193-195.

Nephew, B. C., Kahn, S. A. and Romero, L. M. (2003). Heart rate and behavior are regulated independently of corticosterone following diverse acute stressors. Gen. Comp. Endocrinol. 133, 173-180.

Perneger, T. V. (1998). What's wrong with Bonferroni adjustments. BMJ 316, 12361238

Pilo, B., Etches, R. J. and George, J. C. (1985). Effects of corticosterone infusion on the lipogenic activity and ultrastructure of the liver of laying hens. Cytobios $44179 S$, 273-285.

Quinn, G. P. and Keough, M. J. (eds) (2002). Comparing groups or treatments analysis of variance. In Experimental Design and Data Analysis for Biologists, pp. 173-207. New York, NY: Cambridge University Press.

Reddy, T. E., Pauli, F., Sprouse, R. O., Neff, N. F., Newberry, K. M., Garabedian, M. J. and Myers, R. M. (2009). Genomic determination of the glucocorticoid response reveals unexpected mechanisms of gene regulation. Genome Res. 19, 2163-2171.

Rice, W. R. (1989). Analyzing tables of statistical tests. Evolution 43, 223-225.

Rich, E. L. and Romero, L. M. (2005). Exposure to chronic stress downregulates corticosterone responses to acute stressors. Am. J. Physiol. 288, R1628-R1636.

Rivier, C. and Rivest, S. (1991). Effect of stress on the activity of the hypothalamicpituitary-gonadal axis: peripheral and central mechanisms. Biol. Reprod. 45, 523532 .

Romero, L. M. and Reed, J. M. (2005). Collecting baseline corticosterone samples in the field: is under 3 min good enough? Comp. Biochem. Physiol. 140A, 73-79.

Romero, L. M., Dickens, M. J. and Cyr, N. E. (2009). The Reactive Scope Model - a new model integrating homeostasis, allostasis, and stress. Horm. Behav. 55, 375-

Rothman, K. J. (1990). No adjustments are needed for multiple comparisons. Epidemiology 1, 43-46. 
Rousseau, G. G. and Baxter, J. D. (1979). Glucocorticoid receptors. Monogr. Endocrinol. 12, 49-77.

Ruxton, G. D. and Beauchamp, G. (2008). Time for some a priori thinking about post hoc testing. Behav. Ecol. 19, 690-693.

Sanderson, J. T. (2006). The steroid hormone biosynthesis pathway as a target for endocrine-disrupting chemicals. Toxicol. Sci. 94, 3-21.

Sapolsky, R. M. (1985). Stress-induced suppression of testicular function in the wild baboon: role of glucocorticoids. Endocrinology 116, 2273-2278.

Sapolsky, R. M., Krey, L. C. and McEwen, B. S. (1984). Stress down-regulates corticosterone receptors in a site-specific manner in the brain. Endocrinology 114, 287-292.

Sapolsky, R. M., Romero, L. M. and Munck, A. U. (2000). How do glucocorticoids influence stress responses? Integrating permissive, suppressive, stimulatory, and preparative actions. Endocr. Rev. 21, 55-89.

Schmidt, K. L., Malisch, J. L., Breuner, C. W. and Soma, K. K. (2010). Corticosterone and cortisol binding sites in plasma, immune organs and brain of developing zebra finches: intracellular and membrane-associated receptors. Brain Behav. Immun. 24, 908-918.

Sokal, R. R. and Rohlf, F. J. (1981). Assumptions of analysis of variance. In Biometry, pp. 400-453. New York, NY: W. H. Freeman.

Spencer, R. L., Miller, A. H., Moday, H., McEwen, B. S., Blanchard, R. J., Blanchard, D. C. and Sakai, R. R. (1996). Chronic social stress produces reductions in available splenic type II corticosteroid receptor binding and plasma corticosteroid binding globulin levels. Psychoneuroendocrinology 21, 95-109.

Spencer, R. L., Kalman, B. A. and Dhabhar, F. S. (2001). Role of endogenous glucocorticoids in immune system function: regulation and counterregulation. In Handbook of Physiology, Section 7: The Endocrine System: Coping with the Environment: Neural and Endocrine Mechanisms, Vol. IV (ed. B. S. McEwen and H M. Goodman), pp. 381-423. New York, NY: Oxford University Press.
Tilbrook, A. J., Turner, A. I. and Clarke, I. J. (2000). Effects of stress on reproduction in non-rodent mammals: the role of glucocorticoids and sex differences. Rev. Reprod. 5, 105-113.

Tomas, F. M., Munro, H. N. and Young, V. R. (1979). Effect of glucocorticoid administration on the rate of muscle protein breakdown in vivo in rats, as measured by urinary excretion of $\mathrm{N}$ tau-methylhistidine. Biochem. J. 178, 139-146.

Wada, H. and Breuner, C. W. (2010). Developmental changes in neural corticosteroid receptor binding capacity in altricial nestlings. Dev. Neurobiol. 70, 853-861.

Ward, P. (1969). The annual cycle of the yellow-vented bulbul, Pycnonotus goavier, in a humid equatorial environment. J. Zool. 157, 25-45.

Watson, M. L., Baehr, L. M., Reichardt, H. M., Tuckermann, J. P., Bodine, S. C. and Furlow, J. D. (2012). A cell-autonomous role for the glucocorticoid receptor in skeletal muscle atrophy induced by systemic glucocorticoid exposure. Am. J. Physiol. 302, E1210-E1220.

Wingfield, J. C. and Kitaysky, A. S. (2002). Endocrine responses to unpredictable environmental events: stress or anti-stress hormones? Integr. Comp. Biol. 42, 600609

Wingfield, J. C. and Sapolsky, R. M. (2003). Reproduction and resistance to stress: when and how. J. Neuroendocrinol. 15, 711-724.

Wingfield, J. C., Vleck, C. M. and Moore, M. C. (1992). Seasonal changes of the adrenocortical response to stress in birds of the Sonoran Desert. J. Exp. Zool. 264, 419-428.

Yuan, L, Lin, H., Jiang, K. J., Jiao, H. C. and Song, Z. G. (2008) Corticosterone administration and high-energy feed results in enhanced fat accumulation and insulin resistance in broiler chickens. Br. Poult. Sci. 49, 487-495.

Zuur, A. F., leno, E. N., Walker, N. J., Saveliev, A. A. and Smith, G. M. (2009) Limitations of linear regression applied on ecological data. In Mixed Effects Mode/s and Extensions in Ecology with $R$, pp. 11-33. New York, NY: Springer Science+Business Media 